\title{
Resíduos sólidos urbanos no sertão baiano: um retrato do Município de Barra do Mendes, Estado da Bahia, Brasil
}

\section{Eliane Nunes Sodré Rocha ${ }^{1}$, Airan dos Santos Protázio ${ }^{1}$,*, Denise Costa Rebouças Lauton ${ }^{2}$, Aline Cristina da Silva Moraes ${ }^{1}$ e Arielson dos Santos Protázio ${ }^{3}$}

\author{
${ }^{1}$ Instituto Federal de Educação, Ciência e Tecnologia da Bahia. Rodovia BA-148, km 04, \\ no 1800. Vila Esperança. Irecê-BA, Brasil (CEP 44900-000). *E-mail: \\ airanprotazio@yahoo.com.br. \\ ${ }^{2}$ Universidade Federal da Bahia. Rua Augusto Viana, S/№. Canela. Salvador-BA, Brasil \\ (CEP 40110-909). \\ ${ }^{3}$ Universidade Federal do Recôncavo da Bahia. Rua Rui Barbosa, 710. Centro. Cruz das \\ Almas-BA, Brasil (CEP 44380-000).
}

Resumo. A gestão dos resíduos sólidos urbanos (RSU) no Brasil tem evidenciado graves problemas, sendo alvo de muitas críticas. Contudo, poucas iniciativas ou ideias buscando mitigar a problemática têm sido apontadas. O Município de Barra do Mendes, localizado no sertão baiano, apresenta um cenário similar à da maioria dos municípios brasileiros: existe a produção de uma grande quantidade de resíduos e a inexistência de uma gestão eficiente. Para entender melhor a realidade do Município de Barra do Mendes em relação a gestão dos seus resíduos sólidos, realizou-se observações in situ, análise bibliográfica baseada em leis e normas e a aplicação de questionários do tipo autoaplicado. Diversos problemas relacionados ao manejo dos resíduos sólidos puderam ser registrados no município, desde o transporte, despejo, armazenamento e queima de forma inadequada até a localização inapropriada do lixão, circunstâncias que põem em risco a saúde da população e o meio ambiente. Entretanto, verificou-se que pouca atenção vem sendo dada ao assunto no município, bem como existe pouca apropriação por parte dos morados acerca da coleta, transporte e descarte dos resíduos sólidos produzidos. Salienta-se, portanto, que é preciso pensar na questão dos RSU como um caso de saúde pública, que tem como principais entraves a falta de boa vontade política em priorizar a questão e, consequentemente, disponibilizar verbas necessárias para o desenvolvimento de projetos socioambientais direcionados a conscientização dos habitantes e para a criação de um sistema de tratamento adequado para descarte dos resíduos. Assim, esta discussão consiste em uma importante ferramenta para gestão dos RSU no município.

Palavras-chave: Gestão municipal; Resíduos sólidos; Percepção ambiental; Sustentabilidade.
Recebido: 18/02/2019

Aceito:

11/04/2019

Publicado:

30/04/2019

Acesso aberto

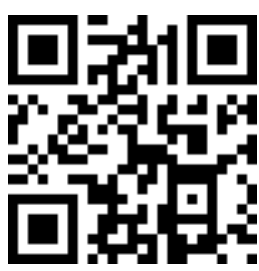

\section{ORCID}

(1) 0000-0002-7788-3310 Eliane Nunes Sodré Rocha

(D) 0000-0003-1864-6574

Airan dos Santos Protázio

(1) 0000-0002-5713-0557 Denise Costa Rebouças Lauton

(D) 0000-0003-4932-7517 Aline Cristina da Silva Moraes 
Abstract. Urban solid wastes in the backlands of Bahia: a portrait of the municipality of Barra do Mendes, Bahia State, Brazil. Urban solid waste management in Brazil has shown serious problems and is the subject of much criticism. However, few initiatives or ideas seeking to mitigate the problem have been pointed out. The Municipality of Barra do Mendes, located in the backlands of Bahia, presents a scenario similar to that of most Brazilian municipalities: there is a large amount of waste produced and there is no efficient management. To better understand the reality of the Municipality of Barra do Mendes in relation to the management of its solid wastes, in situ observations, bibliographic analysis based on laws and norms and the application of self-applied questionnaires were carried out. Several problems related to the management of solid waste could be registered in the municipality, from transport, dumping, storage and burning inappropriate to the location of the dump, circumstances that endanger the health of the population and the environment. However, it has been observed that little attention has been paid to the subject in the municipality, as well as there is little ownership by the residents about the collection, transportation and disposal of the solid waste produced. It should be pointed out, therefore, that it is necessary to think about the issue of the urban solid wastes as a case of public health, whose main obstacles are the lack of political will to prioritize the issue and, consequently, to provide funds necessary for the development of targeted socio-environmental projects aiming at the awareness of the inhabitants and the creation of an adequate treatment system for waste disposal. Thus, this discussion consists of an important tool for solid waste management in the municipality.

Keywords: Municipal management; Solid waste; Environmental perception; Sustainability.

\section{Introdução}

0 consumismo pode ser caracterizado como o combustível que mantem vigente o modelo econômico capitalista nas sociedades contemporâneas. Este modelo econômico é marcado pelo incentivo a compra de produtos dos quais os indivíduos não necessitam ou ao seu consumo mais do que é realmente necessário a sobrevivência (Silva e Flain, 2017). Esta postura consumista tem aumentado, consideravelmente, a quantidade de materiais descartados no ambiente (Mucelin e Bellini, 2008), intensificando à problemática em torno do gerenciamento dos resíduos sólidos
(D) 0000-0002-1709-1063 Arielson dos Santos Protázio urbanos (RSU), materiais resultantes das atividades humana nos centros urbanos, sejam de origem comercial ou doméstica (Almeida et al., 2013) e que, dependendo da forma que é gerenciado, podem trazer diversos impactos negativos ao ambiente (Jacobi e Besen, 2011).

Dentre os principais problemas associados aos RSU podem-se destacar o acúmulo dos materiais, necessitando de áreas cada vez maiores para o seu depósito, a poluição e a contaminação do solo, lençóis freáticos e águas superficiais pelo desprendimento do lixiviado (Lange e Amaral, 2009), a poluição e contaminação do ar, a partir do lançamento de partículas tóxicas na atmosfera, proveniente da decomposição 
da matéria orgânica (Gouveia e Prado, 2010), bem como o favorecimento do aparecimento de doenças a partir da proliferação de agentes infecciosos (Almeida et al., 2013). A Organização Mundial de Saúde copilou uma série de estudos que associaram a ocorrência de diversas doenças no mundo com a presença dos resíduos sólidos (WHO, 2007). Estas evidências demostram que o tema referente aos RSU não deve ser visto apenas como uma questão ambiental, mas também como uma questão social e de saúde pública (Jacobi e Besen, 2011; Gouveia, 2012; Oliva Júnior e Freire, 2013).

No Brasil, a forma comumente utilizada de descarte dos RSU é a sua deposição em ambientes distante das áreas urbanas, como em aterros sanitários, aterros controlados ou em vazadouros a céu aberto, popularmente conhecidos como lixões (IBGE, 2010). Contudo, levando em consideração as duas últimas opções de destinação final dos resíduos, nestas não há impermeabilização do solo ou qualquer sistema apropriado para a proteção do ambiente, circunstância que agrava os impactos negativos associados aos resíduos (Muñoz, 2002). Para se ter uma ideia, cerca de 3.352 municípios brasileiros ainda utilizam aterros controlados ou vazadouros a céu aberto como forma de deposição final dos resíduos produzidos (ABRELP, 2017). Segundo a Secretaria de Desenvolvimento Urbano (SEDUR, 2014), apenas no Estado da Bahia foram identificados aproximadamente 359 lixões, ou seja, $86,3 \%$ dos municípios baianos ainda utilizam estas estruturas como forma de disposição final dos RSU. Dentre os diversos fatores que podem estar atrelados à manutenção deste quadro, pode-se apontar a falta de recursos direcionados às mudanças necessárias no setor (ABRELP, 2017) e a falta de percepção ambiental da população, que desconhece como se dá a gestão do RSU na sua cidade, de modo a não se inserir e nem se envolver na gestão e formulação de políticas públicas ambientais de modo a modificar a realidade vivida (Rodrigues et al., 2012; Gonçalves e Gonçalves, 2013).

Deste modo, a enorme quantidade de resíduos produzidos pela população, somado à ineficiência na gestão dos RSU resulta no quadro observado nas diferentes regiões brasileiras, onde os RSU são coletados, transportados e depositados sem nenhum tipo de cuidado ou tratamento, causando uma série de transtornos à sociedade. Considerando as limitações das opções de destinação final para os resíduos e que o seu inadequado gerenciamento resulta em impactos ao ambiente e a sociedade, deve-se considerar as diretrizes de sustentabilidade, repensar hábitos de consumo e descarte; reduzir o consumo de produtos perecíveis, preferindo os mais duradouros, recusar produtos prejudiciais ao meio ambiente e à saúde, reutilizar o produto, dando vida útil a ele, bem como reciclar qualquer produto, reduzindo assim o consumo de água, energia, matéria-prima e gastos excessivos (Carbone et al., 2017).

\section{Resíduos sólidos no Brasil}

Os resíduos sólidos possuem várias denominações, naturezas, origens e composições (Jacobi e Besen, 2011). A Associação Brasileira de Normas Técnicas (ABNT, 2004), a partir da Norma Brasileira Regulamentadora (NBR) 10004:2004, define resíduos sólidos como:

Resíduos nos estados sólido e semissólido, que resultam de atividades de origem industrial, doméstica, hospitalar, comercial, agrícola, de serviços e de varrição. Ficam incluídos nesta definição os lodos provenientes de sistemas de tratamento de água, aqueles gerados em equipamentos e instalações de controle de poluição, bem como determinados líquidos cujas particularidades tornem inviável $\mathrm{o}$ seu lançamento na rede pública de esgotos ou corpos de água, ou exijam 
para isso soluções técnicas e economicamente inviáveis em face à melhor tecnologia disponível (ABNT, 2004).

A produção de resíduos nas cidades brasileiras é um fenômeno inevitável, que ocorre diariamente, com composição e quantidade que variam de acordo com o tamanho populacional e nível de desenvolvimento econômico da comunidade (Grippi, 2006). De acordo com um levantamento realizado pela Associação Brasileira de Empresas de Limpeza Pública e Resíduos Especiais (ABRELB, 2016), o Brasil produziu em 2017 um total anual de 78,4 milhões de toneladas de resíduos sólidos urbanos, sendo 71,6 milhões de toneladas o montante coletado e 6,9 milhões de toneladas de resíduos que não foram coletados, tendo desta forma um destino impróprio. Uma grande parcela dos resíduos sólidos produzidos não possui destinação sanitária e ambientalmente adequada (Gouveia, 2012). Estima-se que cerca de $63,6 \%$ dos resíduos produzidos no Brasil sejam dispostos a céu aberto, em lixões, 18,4\% sejam dispostos em aterros controlados e $13,8 \%$ encaminhados aos aterros sanitários (Mesquita Júnior, 2007).

0 desenvolvimento, nas sociedades contemporâneas, de um estilo de vida baseado na produção e consumo, aliado a ausência de políticas públicas destinadas a melhorias da gestão dos recursos naturais, provocaram um aumento na geração de resíduos sólidos, tanto em quantidade como em diversidade, principalmente nos grandes centros urbanos (Demajorovic, 1995; Campos, 2012). Além do incremento em volume, o investimento em desenvolvimento tecnológico favoreceu também a produção de resíduos que passaram a abrigar em sua composição elementos sintéticos, muitas vezes perigosos aos ecossistemas e à saúde humana (MMA, 2008), aumentando a gravidade do problema.
Os resíduos sólidos constituem grave problema quando mal gerenciados ou descartados inadequadamente, favorecendo a proliferação de microvetores de agentes etiológicos como a amebíase, a salmonelose, as helmintoses e servindo como criadouros e esconderijos de macrovetores como ratos, que estão envolvidos na transmissão da peste bubônica e leptospirose, e insetos, que podem transmitir a leishmaniose, doença infecciosa altamente perigosa (Besen et al., 2010; Oliva Júnior e Freire, 2013). Os resíduos sólidos também estão associados ao entupimento de bueiros, contaminação de cursos d'água e lençóis freáticos, além de estarem diretamente relacionados a questões sociais ligadas aos catadores de resíduo e as atividades turísticas (Mesquita Júnior, 2007; Gouveia, 2012).

Ainda que tenha ocorrido tardiamente, à concepção do resíduo como problema de saúde pública no Brasil culminou na criação de leis que garantem sua gestão por órgãos públicos. A Lei no 9.605/1998, que trata os resíduos sólidos como uma questão de crime ambiental (Brasil, 1998), e a Lei no $12.305 / 2010$, que instituiu a Política Nacional dos Resíduos Sólidos, tratou da responsabilidade dos geradores e do poder público, assim como sobre a eliminação dos lixões (Brasil, 2010). Contudo, diante da enorme quantidade e diversidade de resíduos produzido nas cidades e os transtornos advindos, é possível perceber a incoerência entre os direcionamentos legais sobre a gestão dos resíduos e a realidade vivenciada nos diferentes municípios brasileiros. A ausência de planejamento, aliada à ineficiência das políticas públicas em fazer cumprir a legislação e à falta de articulação entre os diferentes entes governamentais (federal, estadual e municipal), pode favorecer a má gestão dos RSU nas diferentes regiões brasileiras (Barbosa, 2018). Assim, os RSU são coletados, transportados e depositados sem nenhum tipo de cuidado 
ou tratamento, o que pode resultar em uma série de transtornos socioambientais.

Diante do elencado, fica evidente que os resíduos gerados constituem um grave problema ambiental, de saúde pública e social (Jacobi e Besen, 2011; Gouveia, 2012; Oliva Júnior e Freire, 2013), o que demonstra a necessidade de compreender e disseminar informações acerca dos problemas ocasionados pelos resíduos sólidos, para que trabalhos de conscientização e gestão de resíduos sejam eficazes dentro, sobretudo, de um contexto municipal. Para reduzir significativamente os impactos ao meio ambiente e à saúde pública fazem-se necessária a adoção de padrões de produção e consumo mais sustentáveis (Jacobi e Besen, 2011; Carvalho et al., 2015), que permitam a manutenção dos recursos naturais, afim de garantir um ecossistema social e ambientalmente estável para as presentes e futuras gerações.

Localizado no interior do Estado da Bahia, o Munícipio de Barra do Mendes apresenta cenário similar à de muitos municípios brasileiros: não dispõe de um eficiente sistema de coleta e transporte dos RSU, utiliza vazadouro a céu aberto como alternativa de deposição final dos resíduos e não dispõe de programas socioeducacionais direcionados à sensibilização dos munícipes com relação à problemática dos RSU produzidos em seu território.

$$
\text { o acelerado crescimento }
$$

vivenciado pelo município agrava ainda mais a situação, já que o volume de resíduos produzidos aumenta e satura o lixão local. Ainda que o Município de Barra do Mendes disponha do Plano Municipal de Saneamento Básico (CBHSF, 2016), este, no entanto, não apresenta metas ou estratégias direcionadas a melhor gestão do RSU ou redução dos seus impactos. Tal fato instiga analisar à problemática acerca da produção, coleta, manejo e destino final do RSU no Município de Barra do Mendes, o alinhamento do município em relação à legislação que trata do assunto, bem como a percepção ambiental dos munícipes acerca do RSU, uma vez que a sua impressão sobre o seu ambiente é um sinalizador dos principais problemas sentidos pela comunidade e serve, portanto, como ferramenta para melhor gestão do município (Bezerra et al., 2008).

\section{Material e métodos}

\section{Área de estudo}

Este estudo foi desenvolvido em Barra do Mendes, município situado na microrregião de Irecê no Estado da Bahia, coordenadas geográficas de referência $11^{\circ} 48^{\prime} 37^{\prime \prime} \mathrm{S}$ e $42^{\circ} 03^{\prime} 33^{\prime \prime} \mathrm{O}$ (Figura 1), que apresenta uma população aproximada de 14.560 habitantes (IBGE, 2017). 0 atual lixão do município foi criado no ano de 2010 e está situado na Fazenda Pau D'Arco, localizado a oeste do município. O Plano de Saneamento Básico do Município de Barra do Mendes entrou em vigor em maio de 2016, baseado na Lei no 11.445/2007 (Brasil, 2007), que trata do saneamento básico, e na Lei no 12.305/2010 (Brasil, 2010), que trata da limpeza urbana e manejo de resíduos sólidos. Desta maneira, o município ficou encarregado de elaborar o Plano de Gestão Integrada de Resíduos Sólidos (PGIRS), de modo a gerenciar ações de coleta, transporte e manejo dos resíduos. Contudo, muitos dos problemas outrora observados no município, ainda podem ser constatados em Barra do Mendes, sobretudo referente ao manejo e forma de depósito dos resíduos sólidos, com destaque especial ao atual local de depósito desses resíduos. 


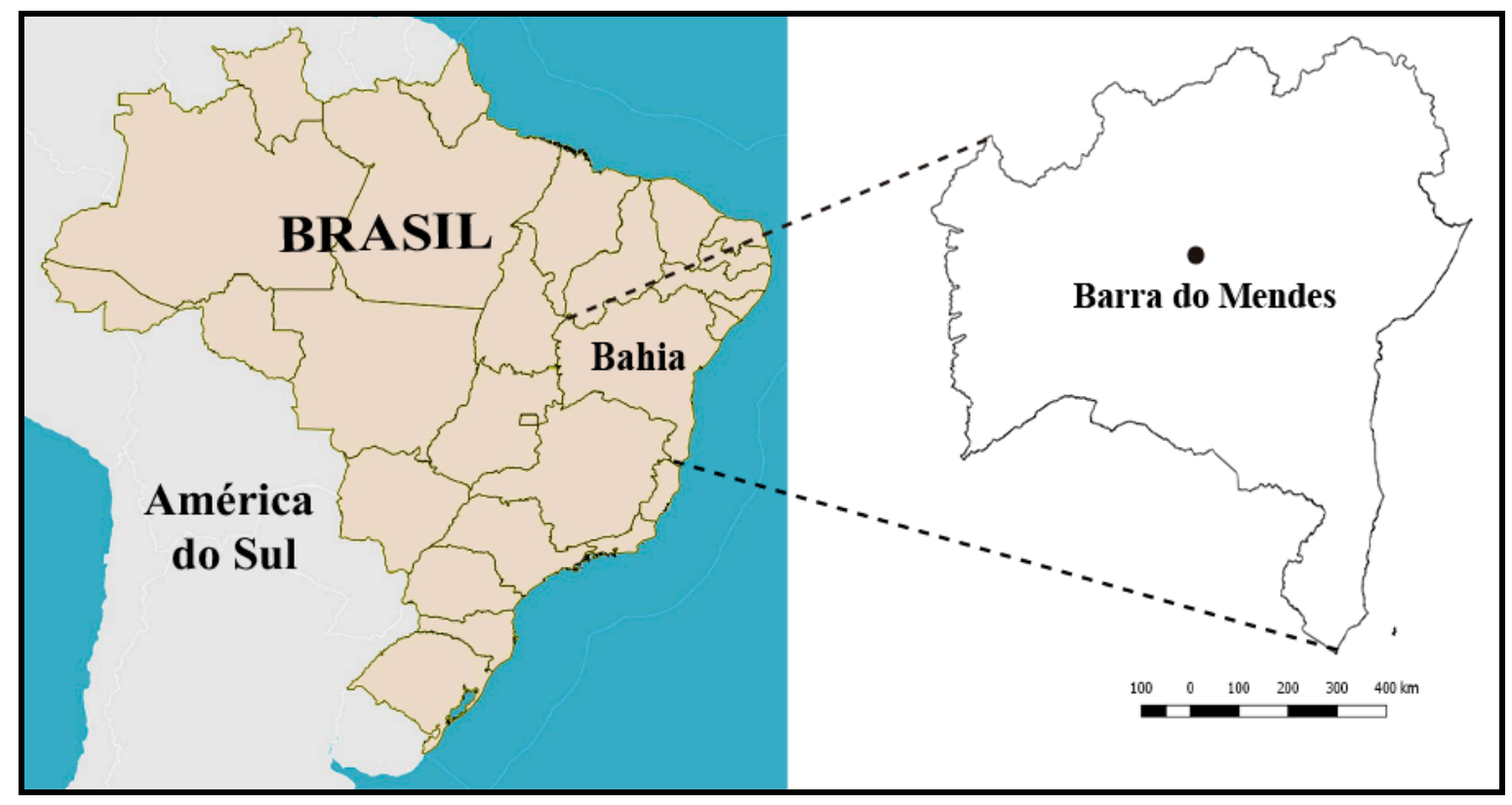

Figura 1. Localização do município de Barra do Mendes, no interior do Estado da Bahia.

\section{Coleta dos dados}

Esta pesquisa é caracterizada como um estudo de caso, o qual tem como objeto estudar as ações referentes ao gerenciamento dos resíduos sólidos urbanos produzidos pelo Município de Barra do Mendes. Para o seu desenvolvimento foram realizadas duas abordagens: (i) observação in situ e análise bibliográfica baseada em leis e normas, utilizada nas questões referentes ao manejo dos resíduos urbanos no município; e (ii) aplicação de questionário do tipo autoaplicado, entregue aos colaboradores pelo pesquisador, cujo objetivo foi levantar a percepção ambiental dos munícipes a respeito dos RSU em Barra do Mendes. As perguntas do questionário foram do tipo fechada, booleana, possibilitando apenas uma resposta (sim ou não), e direta, possibilitando que, depois da resposta opcional "Sim", houvesse um complemento e justificativa à resposta. 0 questionário foi preenchido por 130 colaboradores, de ambos os sexos, maiores de 18 anos de idade que residem em diferentes localidades no município.
Neste trabalho optou-se por realizar uma avaliação local, a fim de notar a atitude dos munícipes acerca do manejo dos resíduos sólidos. Trata-se de uma metodologia inspirada na pesquisa etnográfica, que segundo Silva (2009, p. 175), consiste na "[...] sua circulação no campo, sua observação do campo e sua versão do que aconteceu ali e seus significados". Além das observações corriqueiras, duas visitas foram feitas ao lixão da cidade, uma em agosto de 2016 e outra em janeiro de 2017.

\section{Análise dos dados}

A análise dos dados foi realizada de forma quantitativa e qualitativa. $\mathrm{Na}$ análise quantitativa utilizou-se a inferência estatística descritiva da distribuição de frequência para cada uma das questões elencadas. Já na análise qualitativa utilizou-se uma abordagem comparativa, onde se buscou compreender e interpretar as respostas dos participantes e compará-las a realidade vivenciada pelos munícipes, extraída de visitas in situ ao lixão, assim como de informações encontradas em 
documentos que abordam sobre resíduos sólidos urbanos no município.

\section{Resultados e discussão}

\section{Observação in situ no Município de Barra do Mendes (inspiração etnográfica)}

Com base nas observações in situ, diversos problemas relacionados ao manejo dos resíduos sólidos no Município de Barra do Mendes puderam ser registrados (Figura 2). Pode-se observar o transporte inadequado dos resíduos sólidos no município, no qual uma parcela dos resíduos transportados nos caminhões transborda durante $\mathrm{o}$ carreto, sujando e contaminado as ruas e o solo (Figura 2A). Constatou-se também que o despejo e armazenamento dos resíduos em Barra do Mendes são realizados diretamente sobre o solo em lixões, ou seja, a céu aberto, expondo todo o material e sem a existência de qualquer estrutura que impeça $a$ contaminação do ambiente (Figura 2B). A queima dos resíduos de forma inapropriada também pode ser verificada (Figura 2C). Estas, dentre outras, são circunstâncias observadas em Barra do Mendes que comprometem o meio ambiente e a saúde da população, mesmo diante da existência e atuação da Secretaria de Obras e Serviços Públicos, órgão vinculado à Prefeitura Municipal de Barra do Mendes e que tem a responsabilidade de gerir os resíduos urbanos produzidos no município e zelar pelo saneamento básico.

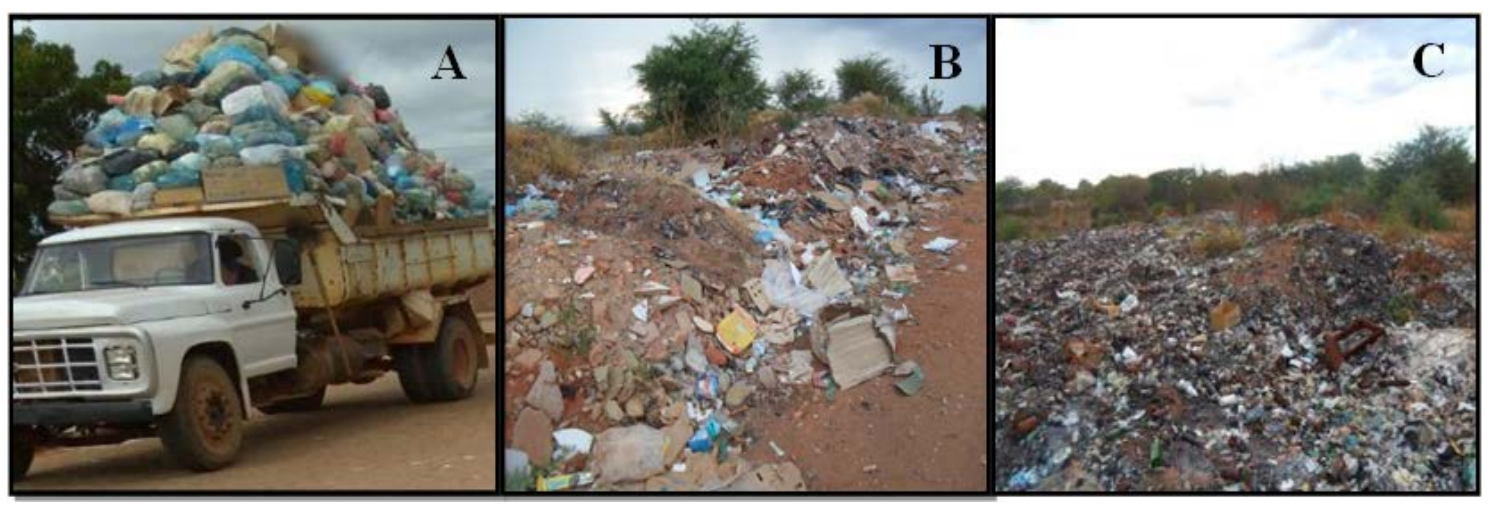

Figura 2. Gerenciamento dos resíduos sólidos no Município de Barra do Mendes. A - Veículo do tipo caçamba basculante utilizado de forma inapropriada; B - Resíduos armazenados no lixão; C - Resíduos queimados no lixão.

Além dos problemas elencados, deve-se considerar que o lixão de Barra do Mendes está localizado na sede do município. Assim, é possível observar diversas casas residenciais nas adjacências do lixão, fato que põe em risco a saúde dos moradores, seja pela contaminação do solo e água, seja pela poluição do ar proveniente da queima dos resíduos ou pela proliferação de animais que podem ser vetores de doenças.

Segundo Gouveia (2012), a disposição de resíduos em lixões a céu aberto é uma forma perigosa de lidar com a questão, pois os resíduos são expostos sem tratamento, situação que pode potencializar seus efeitos contaminantes, favorecer a proliferação de vetores transmissores de doenças e 
intensificar questões sociais ligadas aos catadores de lixo e as atividades turísticas (Gouveia, 2012; Mesquita Júnior, 2007). Não obstante a disposição de resíduos em lixões constituir um grave problema ambiental, de saúde pública e social, é uma das formas de disposição final dos resíduos sólidos urbano comumente utilizada no Brasil (ABRELP, 2017), talvez por ser considerado de baixo custo para instalação e manutenção. Segundo metas estipuladas e ajustadas pelo Plano Nacional de Saneamento Básico (MCIDADES, 2014), o Brasil deveria extinguir até o ano de 2033, todos os lixões existentes em seu território, processo que ocorreria em três etapas: aproximadamente 891 lixões até o ano de 2018; 668 até 2023; e 1.281 até 2033, panorama que conduziria o Brasil há não apresentar mais lixões como forma de disposição final dos resíduos sólidos urbanos. No entanto, percebe-se que no Brasil as ideias relacionadas à extinção dos lixões não se efetivam.

Diversos municípios brasileiros ainda dispõem de lixões para depósito dos resíduos produzidos em seu território (ABRELP, 2017), sem que haja, em muitos casos, qualquer tipo de planejamento ou engajamento para sua substituição a curto, médio ou longo prazo.

\section{Percepções dos moradores sobre os Resíduos Sólidos Urbanos no município de Barra do Mendes}

As respostas dos entrevistados são apresentadas na Figura 3. A análise da percepção dos munícipes de Barra do Mendes acerca dos RSU produzidos pelo município evidenciou desconhecimento referente ao manejo e destinação final dos resíduos sólidos urbanos por uma parcela da população. Através dos questionários, nota-se que apenas $67,7 \%$ dos entrevistados souberam informar onde os RSU do município de Barra do Mendes são depositados e, destes, 64,6\% souberam informar a localização precisa do vazadouro a céu aberto no município.
Apesar de muitos entrevistados desconhecerem a existência e o funcionamento do lixão, a maioria não aprova sua existência, com menos de $1 \%$ de discordância. Em relação a queima do RSU a céu aberto como forma de redução no volume dos resíduos, $73,1 \%$ dos colaboradores não concordam com esta prática, sendo relatado que esta ação pode causar sérios problemas à saúde da população. Como alternativa a este quadro, grande parte dos colaboradores acredita que o aterro sanitário seria à solução mais adequada para a questão dos RSU no município. Paralelamente, estes acreditam que a coleta seletiva consiste em uma estratégia adicional a ser utilizada para minimização dos resíduos destinados aos aterros. Cabe salientar que os munícipes da Barra do Mendes concebem o aterro sanitário compartilhado com outros municípios circunvizinhos como uma alternativa viável a ser implementada no município, já que garantiria a compactação dos resíduos já depositados e a limpeza da área onde se encontra o atual lixão, diminuindo assim a poluição local.

Registrou-se que $71,5 \%$ dos colaboradores sabem o significado do termo reciclagem e $50,7 \%$ do total sabem o conceito de coleta seletiva, entretanto $77,6 \%$ do total de colaboradores desconhecem qual é a finalidade de ambos os processos. Mesmo diante deste fato, todos os entrevistados informaram que o incentivo ao desenvolvimento de projetos que visem orientar os munícipes para as práticas de reciclagem e coleta seletiva são de grande valia uma vez que, além de diminuir a quantidade de resíduos destinados aos aterros e minimizar os riscos ao meio e à saúde da população, podem gerar renda. A implantação de cooperativas com interesse econômico em relação aos resíduos produzidos na cidade, também foi uma alternativa sugerida pelos munícipes. Segundo eles, esta opção pode minimizar o volume de resíduos destinado aos lixões, assim como é uma ótima estratégia de fonte de renda, 
garantindo aos cooperados uma melhoria na qualidade de vida. Segundo o SEBRAE (2012), numerosas oportunidades de negócios giram em torno do gerenciamento dos RSU e do desenvolvimento sustentável. Para a ABRELPE (2017), só em 2015 foram gerados aproximadamente 353,4 mil postos formais de emprego na área da limpeza pública, número que pode ser muito maior quando considerado os trabalhos informais que giram em torno da temática. Tais informações demonstram que os RSU podem servir como fonte de renda para os munícipios e constituir em um mecanismo de inclusão social (Gouveia, 2012), frisando a importância da sua gestão para a manutenção socioambiental.

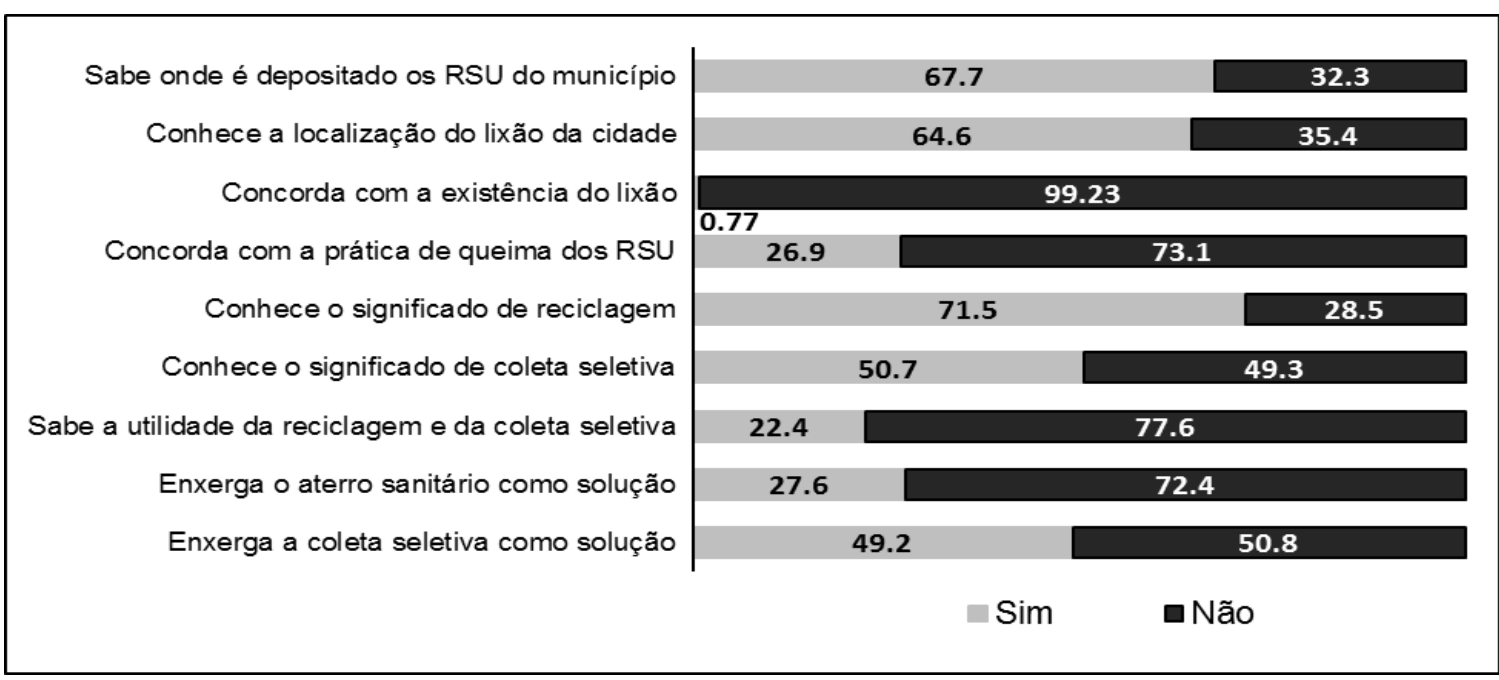

Figura 3. Respostas dos colaboradores em relação aos resíduos sólidos urbanos produzido no Município de Barra do Mendes, Bahia (valores em porcentagem).

\section{Conclusão}

Percebe-se a ausência de alinhamento entre o órgão responsável pelo gerenciamento dos resíduos sólidos no município de Barra do Mendes, a Secretaria de Obras e Serviços Públicos, e as diretrizes estipuladas nas leis e normas nacionais, sobretudo, referentes ao transporte, depósito e manejo dos resíduos sólidos urbanos, demonstrando falta de planejamento e importância despendida a esta problemática. Este cenário intensifica os impactos da má gestão dos resíduos sobre o ambiente e a sociedade, com aumento dos riscos à saúde dos moradores do município. Além disso, foi possível verificar preocupação dos moradores acerca da situação vivenciada no município, principalmente daqueles que vivem próximos ao lixão, ainda que a população entrevistada apresente pouca apropriação de situações corriqueiras vivenciada no município e de termos relacionadas aos RSU. Diante do atual modelo econômico adotado, e tendência ao consumismo exacerbado, existe uma dificuldade nas sociedades contemporâneas em mudar os hábitos que direcionem a redução do consumo e consequente produção dos RSU. Sendo assim, é necessário que o poder público e os munícipes de Barra do Mendes se apropriem de questões referentes à gestão e manejo dos resíduos sólidos produzidos no município, de maneira a contribuir para uma melhor qualidade de vida dos 
habitantes e garantir a conservação dos recursos naturais.

\section{Agradecimentos}

Os autores agradecem aos professores Janaina Novaes Sobrinho, Thiago Edwiges e Denise Pastore de Lima pela leitura do texto e apoio à sua publicação e ao Instituto Federal da Bahia pela concessão de bolsa PINA (Projeto de Incentivo à Aprendizagem) à primeira autora durante o desenvolvimento da pesquisa.

\section{Conflito de interesses}

Os autores declaram não haver conflito de interesses.

\section{Referências}

ABNT - Associação Brasileira de Normas Técnicas. ABNT NBR 10004:2004 Resíduos Sólidos - Classificação. Rio de Janeiro: ABNT, 2004.

ABRELPE - Associação Brasileira de Empresas de Limpeza Pública e Resíduos Especiais. Panorama de Resíduos no Brasil 2017. São Paulo: ABRELPE, 2017.

Almeida, N. R.; Pedrotti, A.; Bitencourt, D. V.; Santos, L. C. P. A problemática dos resíduos sólidos urbanos. Interface Científica, v. 2, n. 1 , p. 25-36, 2013. https://doi.org/ 10.17564/2316-3798.2013v2n1p25-36

Barbosa, L. L. Racionalidade comunicativa ambiental e gestão dos resíduos sólidos em Teresina: encontros e desencontros de sentidos. Teresina: Universidade de Federal do Piauí, 2018. (Dissertação de mestrado).

Besen, G. R; Günther, W. M. R.; Rodriguez, A. C.; Brasil, A. L. Resíduos sólidos: vulnerabilidades e perspectivas. In: Saldiva, P. (Ed.). Meio ambiente e saúde: o desafio das metrópoles. São Paulo: Ex Libris, 2010.

Bezerra, T. M. O.; Feliciano, A. L. P.; Alves, A. G. C. Percepção ambiental de alunos e professores do entorno da Estação Ecológica de Caetés - Região Metropolitana do RecifePE. Biotemas, v. 21, n. 1, p. 147-160, 2008. https://doi.org/10.5007/2175-7925.2008 v21n1p147

Brasil. Lei $\mathrm{n}^{\mathbf{o}}$ 11.445, de 5 de janeiro de 2007. Estabelece as diretrizes para o saneamento básico e dá outras providências. Disponível em: <http://www.planalto. gov.br/ccivil_03/_Ato2007-2010/2007/Lei/ L11445.htm>. Acesso em: 26 set. 2018.

Brasil. Lei no 12.305, de 2 de agosto de 2010. Institui a Política Nacional de Resíduos Sólidos, e dá outras providências. Disponível em: <http://www.planalto.gov.br/ccivil_03/ _ato2007-2010/2010/lei/l12305.htm>.

Acesso em: 2 ago. 2018.

Brasil. Lei no 9.605, de 12 de fevereiro de 1998. Dispõe sobre as sanções penais e administrativas derivadas de condutas e atividades lesivas ao meio ambiente, e dá outras providências. Disponível em: <http://www.planalto.gov.br/ccivil_03/LEIS /L9605.htm>. Acesso em: 26 set. 2018.

Campos, H. K. T. Renda e evolução da geração per capita de resíduos sólidos no Brasil. Engenharia Sanitária Ambiental, v. 17, n. 2, p. 171-180, 2012. https://doi.org/10.1590/ S1413-41522012000200006

Carbone, A. S.; Cezare, J. P.; Ramos, M. F.; Egute, N. S.; Coutinho, S. M. V. 5 Rs: educação para o consumo responsável. São Paulo: Instituto Siades, 2017.

Carvalho, N. L.; Kersting, C.; Rosa, G.; Fruet, L.; Barcellos, A. L. Desenvolvimento sustentável $\mathrm{x}$ desenvolvimento econômico. Revista Monografias Ambientais Santa Maria, v. 14, n. 3, p. 109-117, 2015.

CBHSF - Comitê da Bacia Hidrográfica do Rio Jacaré. Plano Municipal de Saneamento Básico de Barra do Mendes-BA. Barra do Mendes: CBHSF, 2016.

Demajorovic, J. Da política tradicional de tratamento do lixo à política de gestão de resíduos sólidos: as novas prioridades. Revista de Administração de Empresas, v. 35, n. 3, p. 88-93, 1995. https://doi.org/ 10.1590/S0034-75901995000300010 
Gonçalves, I. S.; Gonçalves, V. L. S. Políticas públicas, percepção e gestão ambiental. Planeta Amazônia: Revista Internacional de Direito Ambiental e Políticas Públicas, n. 5, p. 167-177, 2013.

Gouveia, N. Resíduos sólidos urbanos: impactos socioambientais e perspectiva de manejo sustentável com inclusão social. Ciência \& Saúde Coletiva, v. 17, n. 6, p. 503-510, 2012. https://doi.org/10.1590/ S1413-81232012000600014

Gouveia, N.; Prado, R. R. Health risks in areas close to urban solid waste landfill sites. Revista de Saúde Pública, v. 44, n. 5, p. 859866, 2010. https://doi.org/10.1590/S003489102010005000029

Grippi, S. Lixo: reciclagem e sua história Guia para as prefeituras brasileiras. Rio de Janeiro: Interciência, 2006.

IBGE - Instituto Brasileiro de Geografia e Estatística. 2017. Cidades. Disponível em: $<$ https://cidades.ibge.gov.br/brasil/ba/barra -do-mendes/panorama>. Acesso em: $04 \mathrm{fev}$. 2018.

IBGE - Instituto Brasileiro de Geografia e Estatística. Pesquisa Nacional de Saneamento Básico 2008. Rio de Janeiro: IBGE, 2010.

IPEA - Instituto de Pesquisa Econômica Aplicada. Diagnóstico dos resíduos sólidos urbanos. Brasília: IPEA, 2012. (Relatório de Pesquisa).

Jacobi, P. R.; Besen, G. R. Gestão de resíduos sólidos em São Paulo: desafios da sustentabilidade. Estudos Avançados, v. 27, n. 71 , p. 135-158, 2011. https://doi.org/ 10.1590/S0103-40142011000100010

Lange, L. C.; Amaral, M. C. S. Geração e características do lixiviado. In: Gomes, L. P. (Coord.). Resíduos sólidos: estudo de caracterização e tratabilidade de lixiviado de aterros sanitários para as condições brasileiras. Rio de Janeiro: ABE, 2009.

Mesquita Júnior, J. M. Gestão integrada de resíduos sólidos. Rio de Janeiro: IBAM, 2007.
MCIDADES - Ministério das Cidades. Plano Nacional de Saneamento Básico: mais saúde com qualidade de vida e cidadania. Brasília: MCIDADES, 2014. Disponível em: <http://www.cidades.gov.br/saneamentocidades/plansab>. Acesso em: 26 fev. 2019.

MMA - Ministério do Meio Ambiente. Lixo: um grave problema no mundo moderno. Brasília: MMA, 2008. Disponível em: <http://www.mma.gov.br/estruturas/sedr_p roecotur/_publicacao/140_publicacao09062 009031109.pdf>. Acesso em: 10 fev. 2018.

Mucelin, C. A.; Bellini, M. Lixo e impactos ambientais perceptíveis no ecossistema urbano. Sociedade \& Natureza, v. 20, n. 1, p. 111-124, 2008. https://doi.org/10.1590/ S1982-45132008000100008

Muñoz, S. I. S. Impactos ambiental na área do aterro sanitário e incinerador de resíduos sólidos de Ribeirão Preto, SP: avaliação dos níveis de metais pesados. São Paulo: Universidade de São Paulo, 2002. (Tese de doutorado).

Oliva Júnior, E. F.; Freire, R. S. Os impactos ambientais decorrentes da produção de resíduos sólidos urbanos e seus riscos à saúde humana. Revista Eletrônica da Faculdade José Augusto Vieira, n. 8, p. 158171, 2013.

Rodrigues, M. L.; Malheiros, T. F.; Fernandes, V.; Darós, T. D. A percepção ambiental como instrumento de apoio na gestão e formulação de políticas públicas ambientais. Saúde e Sociedade, v. 21, supl. 3, p.91-110, 2012. https://doi.org/10.1590/S010412902012000700009

SEBRAE - Serviço Brasileiro de Apoio as Micros e Pequenas Empresas. Gestão de resíduos sólidos: uma oportunidade para o desenvolvimento municipal e para as micro e pequenas empresas. São Paulo: Instituto Envolverde, 2012.

SEDUR - Secretaria de Desenvolvimento Urbano do Estado da Bahia. Regionalização da gestão integrada de resíduos sólidos do Estado da Bahia. Salvador: SEDUR, 2014. Disponível em: <http://www.sedur.ba. gov.br/modules/conteudo/conteudo.php?co nteudo=22>. Acesso em: 13 dez. 2018. 
Silva, H. A. Situação etnográfica: andar e ver. Horizontes Antropológicos, v. 15, n. 2, p. 171-188, 2009. https://doi.org/10.1590/ S0104-71832009000200008

Silva, M. B. O.; Flain, V. S. Capitalismo e consumismo: os desafios do consumo sustentável na sociedade contemporânea. Revista da AJURIS, v. 44, n. 143, p. 357-378, 2017.

WHO - World Health Organization. Population health and waste management: Scientific data and policy options. Roma: WHO, 2007. Disponível em: <http://www.euro.who.int/_data/assets/pd f_file/0012/91101/E91021.pdf>. Acesso em: 23 jan. 2019.

Informação da Licença: Este é um artigo Open Access distribuído sob os termos da Licença Creative Commons Attribution, que permite uso irrestrito, distribuição e reprodução em qualquer meio, desde que a obra original seja devidamente citada. 